\title{
Os interesses econômicos dos Estados Unidos e a segurança interna no Brasil entre 1946 e 1964: uma análise sobre os limites entre diplomacia coercitiva e operações encobertas
}

\section{PAULO ROMEU BRAGA*}

\section{Introdução}

Certa feita, os jornais brasileiros publicaram que Henry Kissinger teria dito em uma conferência, após sua saída do governo, que o Brasil desenvolvido seria uma ameaça para a segurança de seu país. Embora houvesse o desmentido de praxe, o que Kissinger queria dizer com isso? Por que o desenvolvimento do Brasil poderia ser uma ameaça para a segurança nacional norte-americana? Como se sabe, Kissinger foi dirigente do National Security Council (NSC) no primeiro mandato de Nixon e acumulou essa função com a de secretário de Estado no segundo governo daquele presidente. Em 1974, o memorando secreto NSSM-200, do NSC, desclassificado em 1989 por força da lei de liberdade de informação, fornecia as evidências básicas para interpretarmos as palavras de Kissinger.

A economia norte-americana era cada vez mais dependente de recursos naturais do exterior para garantir o seu desenvolvimento, e isso foi oficializado no NSSM-200 emitido pelo governo norte-americano. O NSSM-200 fixava uma política para garantir o fluxo contínuo de materiais para o desenvolvimento da economia norte-americana: “A localização de reservas conhecidas de minérios de mais alto teor da maioria dos elementos favorece uma dependência crescente de todas as regiões industrializadas de importações dos países menos desenvolvidos. O problema real de suprimentos minerais reside, não na disponibilidade física básica, mas nos temas econômico-políticos relativos ao acesso a eles, os termos de exploração e divisão dos benefícios entre os produtores, consumidores e os governos dos países 
de origem.” Prosseguindo diz o memorando: "Sejam quais forem as medidas que se tomem para resguardar-se de uma interrupção nos fornecimentos, a economia norte-americana requererá grandes e crescentes quantidades de recursos minerais do exterior, especialmente dos países menos desenvolvidos. Este fato amplia o interesse dos Estados Unidos na estabilidade social, política e econômica dos países fornecedores.” O documento relacionava os treze países-chave considerados de especial interesse estratégico e político para os Estados Unidos: Brasil, Índia, Bangladesh, Paquistão, Nigéria, México, Indonésia, Filipinas, Tailândia, Egito, Turquia, Etiópia e Colômbia.

Essa preocupação manifesta com a estabilidade interna dos países fornecedores de matérias-primas para a economia norte-americana, materializouse no Brasil, no período compreendido pela presente análise (1946/1964), por meio de investimentos privados e programas econômicos, pela firme presença do Departamento de Estado e pelo suporte de segurança a essas políticas engendrado pelo NSC. O que se pretende apresentar neste texto é a estratégia que os governos estadunidenses elaboraram e desenvolveram com eficácia, para conduzir a segurança interna brasileira em acordo com seus interesses.

\section{O desenvolvimento da estratégia}

Embora o NSC tenha fixado através do NSSM-200 uma diretriz básica de segurança, em 1974, quanto à questão do acesso às fontes de recursos naturais, a preocupação com o assunto é bem mais antiga. Na década de 1940, o governo norte-americano, interessado no estudo dos minerais estratégicos para a defesa continental, enviou ao Brasil três ilustres técnicos: Charles Will Wright, especialista em minerais estratégicos, do U.S. Bureau of Mines, Stephen R. Capps e William Drumn Johnston Jr., geólogos conceituados do U.S. Geological Survey, para colaborarem com seus colegas brasileiros nas determinações de nossas reservas minerais. Em 1941, os Drs. Wriht e Johnston passaram a chefiar as pesquisas na América do Sul. Frank Gray Pardee, do Serviço Geológico do Estado de Michigan, foi comissionado pelo U.S. Bureau of Mines para dar assistência à Embaixada Americana no Rio de Janeiro. John Van Nostrand Dorr II, assistido por sua esposa Mary Elizabeth Dorr, paleontologista, e pelo engenheiro C. Buckey, topógrafo, estudaram minuciosamente o depósito manganesífero de Urucum, em Mato Grosso. Em 1942, Buckey realizou, na Divisão de Geologia e Mineralogia, um curso sobre topografia para fins de geologia, introduzindo o método de levantamento a prancheta, pouco divulgado no País. William Pecora, também do U.S. Geological Survey, estudou pormenorizadamente os depósitos niquelíferos do Brasil, especialmente os da Serra da Mantiqueira, em São José do Tocantins, Goiás. Rápida passagem pelo Brasil tiveram, em janeiro de 1942, o Dr. Elmer W. Peherson, chefe da Divisão Econômica do U.S. Bureau of Mines, e o Dr. Donnel Foster Hewett, chefe da 
Divisão de Metais do U.S. Geological Survey e a maior autoridade dos Estados Unidos em manganês. O prof. W. D. Johnston continuou no Brasil estudando os depósitos de cromita, os pegamatitos produtores de tantalita, berilo etc., tendo apresentado à Academia Brasileira de Ciências uma interessante contribuição sobre a gênese dos depósitos estratificados de cromita, na sua opinião, provenientes de uma verdadeira sedimentação rítmica em câmara magmática. Posteriormente, uma turma numerosa de outros técnicos aqui aportou, subordinada ao magnata Nelson Rockefeller, coordenador do Office of the Coordinator of Inter-American Affairs (OCIAA) ${ }^{1}$.

Rockefeller havia conseguido esse cargo de dirigente do OCIAA no governo Eisenhower, depois de convencê-lo de que os Estados Unidos precisavam olhar com mais carinho a América Latina. Nelson tinha grandes negócios aqui e através do Instituto de Assuntos Inter-Americanos (1942/50), organismo ligado ao OCIAA, já defendia, na ocasião, a assistência técnica para a segurança interna dos países do continente. Era natural que houvesse essa preocupação com a segurança interna dos países da região. Em 1960, investidores norte-americanos controlavam 85\% das fontes de matérias-primas na América Latina. No início da década de sessenta, 97,3\% do minério de ferro brasileiro estava sendo explorado por companhias controladas por grupos estrangeiros: dos Estados Unidos havia a Hanna Mining, a U.S. Steel e a Bethlehem Steel; da Alemanha a Mannesman e da Bélgica a Belgo Mineira.

Essa preocupação com a segurança interna dos países da região tomou corpo depois que o exército nazista invadiu a Dinamarca, em abril de 1940. Os estrategistas norte-americanos afirmavam que a fraqueza econômica e militar da América Latina era uma ameaça direta à segurança nacional dos Estados Unidos. “A miséria resultante do atraso econômico (...) poderia propiciar revoluções lideradas por nacionalistas, socialistas ou simpatizantes do nazi-fascismo, movimentos que punham em xeque os interesses dos Estados Unidos. Quase um milhão de alemães habitavam a atual Região Sul do Brasil, considerada cabeça-de-ponte para a ocupação do Atlântico Sul pelos germânicos (...). Dentre as várias possibilidades consideradas pelo Office Strategic Service (OSS), uma delas foi a invasão do Rio Grande do Sul”2 .

Em decorrência, no acordo de cooperação militar formalizado durante a Segunda Guerra, o Brasil veio a ocupar um importante papel como grande fornecedor de matérias-primas e minerais estratégicos para o desenvolvimento da economia e segurança norte-americana. Finda a Guerra, já estava definida a função que a América Latina teria dentro da zona de influência global dos Estados Unidos. Em 1949, o Departamento de Estado havia decidido que a América Latina deveria constituir-se em reserva estratégica para garantir o poderio econômico e militar dos Estados Unidos dentro do novo arranjo mundial que deu origem à Guerra Fria. Em documentos que instruíam as delegações dos Estados Unidos a conferências 
econômicas interamericanas, aos quais a chancelaria brasileira teve acesso por influência pessoal do cônsul-geral em Nova Iorque, estava explícita essa decisão. O chefe da delegação brasileira à segunda sessão da Comissão Econômica para a América Latina (CEPAL), Carlos Alves de Souza, antevendo o contencioso dos próximos anos, assim analisava a questão em correspondência enviada ao ministro interino das Relações Exteriores, Cyro de Freitas Vale:

“A análise da documentação que estou transmitindo a Vossa Excelência revelará que se abre para as relações entre o Brasil e os Estados Unidos da América uma fase nova, e que talvez se revele extremamente árdua e delicada, pois o Departamento de Estado procura, visivelmente, manter a América Latina numa posição de inferioridade, condicionando o seu desenvolvimento à capacidade exclusiva dos investimentos privados.” ${ }^{3}$

No entanto, a surpresa e a indignação que possa ter causado essa descoberta, aparentemente não esmoreceu os propósitos dos governos brasileiros que, com foco na ideologia nacional-desenvolvimentista, já vinham colocando em prática uma política contrária a que Washington havia estabelecido para a América Latina. Desde o primeiro governo de Getúlio Vargas até João Goulart, com exceção de Dutra e Café Filho, a aposta era na expansão da base industrial, diversificação do comércio exterior e no desenvolvimento de uma política externa independente o que, de certa forma, viria a preencher alguns espaços onde os Estados Unidos precisavam circular com desenvoltura. Os fatos de a primeira indústria automobilística a instalar-se no Brasil, durante o governo de Juscelino Kubistchek (JK), ser de origem européia, e de Che Guevara ser condecorado por Jânio Quadros, com a mais alta honraria brasileira, são bastante elucidativos das políticas desenhadas para o período. O país estava fazendo um esforço para deixar de ser apenas um fornecedor de matérias-primas. A proposta era desenvolver-se rapidamente e projetar-se no cenário internacional. Juscelino Kubistchek resumiu muito bem a idéia em sua propaganda de governo: "Cinqüenta anos em cinco".

A posição de confronto velado assumida pelo Brasil, negando-se implicitamente a concorrer para o estabelecimento da Doutrina de Reserva Estratégica formulada por Washington, não passou desapercebida e viria a ter, ao longo dos anos, respostas que afetariam fortemente a sociedade brasileira. Embora Vargas tenha sido forçado por militares a abandonar o poder após a promulgação da Constituição de 1946, a primeira grande reação durante o período considerado foi o “Golpe de 1954”, que culminou com o suicídio de Getúlio e levou ao poder o vice-presidente João Café Filho. Revelando sua posição favorável ao golpe, Café Filho repudiou o programa de governo nacionalista que o havia eleito junto com Vargas e formou o novo ministério convocando, entre outros, Raul Fernandes, político de oposição ligado ao partido União Democrática Nacional (UDN), advogado de empresas internacionais e Clemente Mariano, representante dos 
setores mercantilistas e ligado ao sistema financeiro internacional ${ }^{4}$. Em uma alusão a suas claras preferências, o novo presidente do Brasil ficou conhecido em alguns círculos jornalísticos como "John Coffe Filho”.

A partir do movimento que se iniciou em 1946 e do retorno de Vargas ao poder pela via eleitoral, os assuntos internos brasileiros passaram a ser observados com especial interesse. Os discursos de campanha de Vargas, nas eleições presidenciais de 1950, eram acompanhados pelos órgãos de segurança norteamericanos. O memorando confidencial que o secretário de Estado Dean Acheson enviara ao presidente Truman, em primeiro de maio de 1950, alertava para a política nacionalista que seria implementada pelo futuro presidente do Brasil. Acheson foi conclusivo: "caso Vargas ganhasse as eleições, seu programa de governo entraria em rota de colisão com a política que estamos tentando propagar no campo das

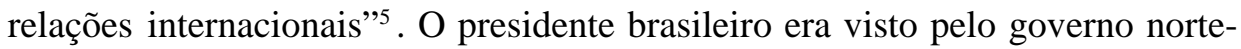
americano como mais preocupado em fortalecer as bases de sua ideologia nacionalista do que combater o comunismo. Nesse sentido, o Brasil era uma dupla ameaça sob o ponto de vista ideológico e a Doutrina de Contenção elaborada por George Kennan em 1946, viria a ser bastante útil.

A doutrina de Kennan baseava-se na premissa de que a longo prazo a União Soviética iria expandir sua influência, reconhecendo, no entanto, que nem todas as partes do mundo seriam vulneráveis a golpes comunistas, por isso os recursos de contenção dos Estados Unidos deviam ser seletivos, concentrando-se nos países estratégicos que possuíam capacidade industrial ou matérias-primas de valor. Para Kennan, os soviéticos iriam expandir sua influência colocando os recursos psicológicos e políticos como prioridade acima dos recursos militares. Assim, Washington deveria elaborar programas de contenção que promovessem a capacidade de segurança interna dos países vulneráveis ${ }^{6}$. No segundo mandato de Truman (1949/53), com o entrelaçamento das doutrinas de Contenção e de Reserva Estratégica aliadas com o Programa do Ponto Quatro, que veio a ser substituído pela United States Agency for International Development (USAID), os Estados Unidos passaram a contar com uma organização que permitiu legitimar o planejamento de segurança para a América Latina.

Quando ocorreu o “Golpe de 1954”, os Estados Unidos já haviam montado uma ampla estrutura de segurança exclusivamente para cuidar da América Latina. A base para a fundamentação dessa decisão adveio das reuniões de consultas dos chanceleres americanos, que geraram o Tratado Interamericano de Assistência Recíproca (TIAR), assinado em 1947 no Rio de Janeiro. Uma das ambigüidades do TIAR é que ele poderia ser usado contra os governos que o haviam assinado, com exceção dos Estados Unidos. A primeira missão naval dos Estados Unidos na América Latina se instalara no Brasil em 1922. Até 1942 os oficiais brasileiros eram treinados na Alemanha ou com os franceses, que mantiveram uma missão no Brasil entre 1919 e 1940. A Segunda Guerra mundial deu a Washington uma 
justificativa para expandir mais sua influência sobre as forças brasileiras. O planejamento militar era coordenado por uma Comissão Militar Mista Brasil/Estados Unidos. Em 1949, o Pentágono ajudou o Brasil a fundar e equipar uma cópia do U.S. National War College, a Escola Superior de Guerra (ESG). Militares norteamericanos permaneceram no corpo docente da ESG até $1960^{7}$. A Comissão Militar Mista sobrevivera a guerra e, em 1954, foi registrada nas Nações Unidas como agência permanente, destinada a cuidar das vendas de armamentos e da assistência militar.

A participação da Força Expedicionária Brasileira (FEB) na Itália propiciou estreito relacionamento e amizades prolongadas entre oficiais brasileiros e norteamericanos. O relacionamento pessoal entre Castelo Branco e Vernon Walters veio a configurar-se, em 1964, como um importante trunfo para os norte-americanos. Vários oficiais brasileiros que haviam estado na campanha da Itália foram enviados aos Estados Unidos para treinamento, de onde voltaram com novas idéias sobre desenvolvimento industrial e organização política do país. Os oficiais, influenciados pelos acontecimentos da Segunda Guerra e decididamente opostos a Getúlio Vargas, a quem consideravam como chefe de um regime neofacista, conspiravam contra ele. Getúlio Vargas defendia uma economia nacionalista estatizante e antes que implementasse seu plano foi deposto pelos oficiais da FEB alinhados com os industriais locais, a oligarquia, a classe média e as empresas multinacionais. O marechal Dutra, que sucedeu a Vargas em 1946, abriu a economia ao capital estrangeiro, criou a ESG e estabeleceu a Comissão Mista Brasil/Estados Unidos.

Ao mesmo tempo que essas iniciativas eram tomadas no Brasil, os Estados Unidos começaram a criar uma infra-estrutura de treinamento militar para todo o continente. Em 1949, a Escola das Américas, que mais tarde ficou conhecida como a "escola de ditadores" (em uma referência aos ditadores latino-americanos que por ali passaram), foi inaugurada em Fort Gulick, na Zona do Canal do Panamá, para ministrar cursos exclusivamente em espanhol e português. Em 1952, uma escola de guerrilheiros da selva foi inaugurada em Fort Sherman, também no Panamá. Os cursos de treinamento para aviadores latino-americanos, na Base Albrook da força aérea, no Panamá, datavam de 1943. De todos, o mais importante treinamento era ministrado em Fort Leavenworth - Kansas e muitos dos oficiais que conspiraram contra o presidente João Goulart foram treinados ali. “Aqueles homens saíam de Leavenworth” - disse certa vez um general norte-americano que servira naquela instalação militar - "com um ardente desejo de se identificar com os Estados Unidos e receber armas de seus colegas norte-americanos"8. O general Amaury Kruel treinou durante três meses em Leavenworth, em 1943, juntamente com dez colegas oficiais do Exército Brasileiro. Kruel, enquanto coronel, veio a ser chefe da Seção de Inteligência da FEB e, em 1958, Chefe de Polícia do Distrito Federal. No entanto, em 1964, Kruel hesitou em se posicionar contra João Goulart. 
Em documento enviado, em 1942, ao general William Donovan, dirigente do Office of Coordination of Information (COI), mais tarde transformado no OSS, Edgar Hoover, diretor do FBI, cita Juracy Magalhães como uma fonte confidencial confiável. Neste ano Magalhães foi promovido a major e mudou-se para os Estados Unidos, onde cursou o Comand and General Staff School, em Fort Leavenworth. No governo Castelo Branco, Juracy Magalhães veio a ser nomeado embaixador em Washington, onde se reaproximou de políticos norte-americanos, entre eles Adolf Berle, que havia sido embaixador no Brasil durante o Governo Vargas na década de 1940. O senador Juracy Magalhães, filho do general, não negou que seu pai conspirou contra Vargas: "Naquela época, de divisão entre leste e oeste, meu pai sempre ficou com os Estados Unidos.” Juracy também foi íntimo do general Vernon Walters $^{9}$. Em março de 1972, o presidente Richard Nixon nomeou o major general Vernon Walters para o cargo de diretor de operações da Central Intelligence Agency (CIA). Walters foi adido militar no Brasil, no posto de coronel, durante o governo Goulart, intérprete do presidente Eisenhower, quando de sua visita ao Brasil, e dos diálogos entre Nixon e o presidente Médici, em Washington. Sua carreira de oficial de inteligência começou durante a Segunda Guerra em Casablanca $^{10}$. Também o general Heitor Herrera, que veio a ser um dos líderes do Instituto de Pesquisa e Estudos Sociais (IPES) ${ }^{11}$ depois de sua aposentadoria no Exército, e que trabalhava na empresa Listas Telefônicas Brasileiras, de propriedade de Gilbert Huber Jr., foi um dos militares brasileiros treinados no U.S. Command and General Staff College, em Fort Leavenworth ${ }^{12}$. As listas telefônicas e as demais companhias do setor, sempre foram altamente relevantes para auxiliar as investigações do staff de segurança.

Robustecendo a estratégia de segurança desenvolvida pelo Pentágono, amparada pela Doutrina de Contenção, também a CIA possuía suas estruturas montadas na América Latina. Em 1955, o oficial de inteligência Byron Engle foi encarregado pelo NSC dos Estados Unidos de organizar uma força tarefa para treinar as polícias da Ásia, África e "especialmente da América Latina”. O organismo, que ficou conhecido como Office of Public Safety (OPS) e que estava acobertado dentro da USAID, oficialmente foi entregue ao Departamento de Estado como parte do programa de ajuda externa. Segundo Langguth, J. Edgar Hoover, diretor do FBI, disse aos seus companheiros que "o programa policial não passava de mais uma operação secreta da CIA”. Hoover estava correto em sua afirmação, pois diversos ex-oficiais do Special Intelligence Service (SIS) do FBI, criado em 1940, que operaram em cima dos nazistas na Argentina e no Brasil durante a Segunda Guerra, haviam-se passado para a CIA por ocasião da sua fundação em 1947. Esses ex-policiais integravam a Divisão do Hemisfério Ocidental da CIA e utilizavam-se do OPS como cobertura.

Antes mesmo da criação do OPS, já havia uma forte relação entre policiais brasileiros e o governo dos Estados Unidos. Em 1942, o embaixador norte-americano 
no Brasil, Jefferson Caffrey, insistiu com Alcides Etchegoyen, chefe do Departamento de Ordem Política e Social (DOPS) do Distrito Federal, para que demitisse imediatamente de seu departamento dez policiais pró-nazismo. Etchgoyen, não só acatou o conselho do embaixador como também deu à embaixada dos Estados Unidos o poder de coordenar o trabalho de contra-espionagem no Brasil, até que ele pudesse organizar uma estrutura voltada para essa área ${ }^{13}$. Ao que se sabe, o Serviço Federal de Informações e Contra-Informações (SFICI), que foi a organização brasileira criada para atuar também em contra-espionagem, somente veio a ser instalado anos mais tarde. Etchegoyen foi nomeado chefe do DOPS em substituição a Filinto Müller, também acusado de pró-nazismo.

O OPS tinha duas principais funções: permitir que a CIA infiltrasse agentes nas polícias locais e recrutar candidatos. Além dos cursos na Academia Internacional de Polícia, a CIA enviava policiais estrangeiros ao seu centro clandestino em Washington. Lá, sob a fachada de International Police Services Inc., policiais da Ásia, da África e da América Latina eram treinados em métodos de vigilância, uso de informantes e outras atividades policiais. Tudo se processava como se o curso fosse também administrado através da USAID ${ }^{14}$. Até 1959, a missão da organização sob a direção de Engle, que operou no Brasil, era combater o comunismo e a subversão, tendo sido ampliada, nessa ocasião, para combater interesses nocivos aos Estados Unidos.

Um dos métodos utilizado pela CIA para recrutar policiais a seu serviço, baseava-se em atacar a debilidade orçamentária das repartições policiais. Assumindo atitudes de negociador, o oficial da CIA colocava as dificuldades para se montar uma nova repartição, processo ou operação, mas deixava em aberto nas entrelinhas que, como parte das informações recolhidas seriam úteis para Washington, era justo que o Governo dos Estados Unidos pagasse parte da conta. Mordida a isca, a CIA entregava uma quantia em dinheiro superior às estimativas, e o policial era estimulado a não prestar conta do excedente dos custos. Conforme a reação do policial que estava sendo subornado, o oficial da CIA ia aumentando os pagamentos mensais, até o momento em que ele, não tendo como voltar atrás, compreendia que estava trabalhando para o Governo dos Estados Unidos. Naturalmente, com a fartura de recursos financeiros proporcionados pela CIA, o policial tendia a mostrar eficiência em seu trabalho e, conseqüentemente, ia galgando postos na hierarquia governamental, o que aumentava o raio de ação e a qualidade da infiltração da CIA.

A CIA também estendia suas operações para outros segmentos da sociedade. Thomas W. Braden, diretor da Divisão de Organização Internacional da CIA de 1951 a 1954, afirmou que entregara pessoalmente cinqüenta mil dólares a Walter e Victor Reuther, da Associação dos Trabalhadores Automobilísticos Unidos. Apontou ainda vários pagamentos feitos para as atividades no exterior de Jay Lovestone e Irving Brow, que dirigiam os negócios internacionais da American Federacion of Labor (AFL-CIO) ${ }^{15}$. É do conhecimento no meio sindical brasileiro, 
que a AFL-CIO cooperou intensamente com os sindicatos de trabalhadores que atuavam no Brasil dentro da diretriz "anticomunista”.

Amparado pelas informações da CIA e em uma vigorosa ação política, Robert Kennedy, secretário de Justiça, irmão do presidente, que chegou a ser cogitado para dirigir a agência, esteve oficialmente no Brasil em dezembro de 1962; em conversa com João Goulart fez abertas ameaças caso o presidente brasileiro continuasse "flertando com causas românticas de esquerda" ${ }^{16}$. Bobb Kennedy sabia o que estava falando, pois exercia forte influência na aprovação de operações encobertas. "Segundo Christopher Andrew, nos dois primeiros anos do governo Kennedy foram aprovadas quinhentas e cinqüenta operações encobertas, mais do que fora iniciado no governo Eisenhower e muito mais do que seria concebível sob Truman"17. A CIA começou a valer-se de operações encobertas desde a sua fundação em 1947. Nesse ano os comunistas ameaçavam chegar ao poder na Itália, então a CIA, secretamente, organizou uma campanha que culminou com a derrota dos comunistas nas urnas. Nas décadas de 1950 e 1960, os Estados Unidos utilizavam-se de operações encobertas combinadas com outras ferramentas de política externa, muito embora a organização da atividade de inteligência norteamericana remontasse à década anterior.

Nesse sentido o presidente Truman criou por decreto, em 22 de janeiro de 1946, a Administração Nacional de Inteligência e subordinado a esta, o Grupo Central de Inteligência, antes mesmo da criação da Lei de Segurança Nacional. O Grupo Central de Inteligência foi o sucessor do OSS e precursor da CIA. Com a possibilidade dos comunistas ganharem as eleições italianas em 1948, e com a hesitação dos ricos industriais de Milão com medo de sofrerem represálias caso os comunistas vencessem, a elite americana optou por uma ação secreta em sentido contrário e fez uma subscrição no Clube Brook de Nova Iorque. Mas Allen Dulles, diretor central da recém criada CIA, "julgava que o problema não podia ser manobrado com eficiência por mãos de particulares. Recomendou empenhadamente que o governo criasse uma organização clandestina”. Por ser uma organização financiada com fundos não oficiais o governo criou uma agência de operações, dentro do NSC, com o título inócuo de Seção de Coordenação de Política, tendo autoridade para realizar operações especiais, secretas e suficientemente reduzidas para que o governo pudesse plausivelmente desmenti-las. O Congresso ratificou formalmente o uso de fundos não registrados com a Lei de Informação Central de 1949. A lei conferia poderes ao Diretor Central de Inteligência (DCI) para efetuar despesas sem atender aos dispositivos legais e aos regulamentos relativos ao gasto de fundos do governo. A assinatura do DCI em qualquer cheque, por mais elevada que fosse a importância, era considerada um registro suficiente ${ }^{18}$. A Seção de Coordenação de Política logo após ficou subordinada à CIA e a lei de 1949 oficializou o financiamento da agência pela elite norte-americana ao aceitar o uso de fundos não registrados. Tal modelo, embora não oficializado, veio a ser aplicado no Brasil, 
no pós 1964, quando empresas nacionais e estrangeiras contribuíam financeiramente para a realização das atividades da "Operação Bandeirantes” (OBAN).

No plano empresarial, Nelson Rockefeller já havia dado a partida muito antes para influenciar na segurança interna brasileira. Apesar de ser republicano, Nelson doou vinte e cinco mil dólares para a campanha do democrata Roosevelt que foi reeleito. A partir daí começou sua influência na política dos Estados Unidos para a América Latina. O plano de Rockefeller era impedir o crescimento do comércio e da influência do eixo nazi-fascista na região, adequando a política americana aos movimentos nacionalistas, em vez de combatê-los. Através da integração entre empresas e governo, o plano previa, entre outras coisas, a redução de taxas de importação sobre produtos latino-americanos, incentivo aos investimentos, com o objetivo de assegurar a produção de matérias-primas, a criação de um sistema de transporte adequado ao escoamento da produção e a flexibilização na análise da dívida externa.

Roosevelt aprovou o plano Rockefeller e criou o Office for Coordination of Commercial and Cultural Relations Between the Americas, cuja direção foi entregue ao milionário, e que mais tarde mudou o nome para OCIAA. “A organização semimilitar da Fundação Rockefeller modelou o funcionamento da agência capitaneada por Nelson”. Além de controlar a expansão das ideologias nocivas aos interesses dos Estados Unidos na região, o objetivo do OCIAA era "afastar da América Latina os produtos alemães que concorriam com os americanos" e garantir o fornecimento de produtos estratégicos. "Nelson acreditava que o futuro desses empreendimentos na América Latina dependia da venda não só de produtos americanos, mas também do modo de vida americano. Tinha, portanto, consciência de que o sucesso no campo econômico tornava necessária uma base sólida no campo ideológico. E, para ele, a comunicação incluía o serviço de inteligência. Em outras palavras, significava também espionagem. Não era gratuita a amizade de Nelson Rockefeller com J. Edgar Hoover, chefe do FBI ${ }^{19}$.

Em 1942, foi criado o Office of War Information (OWI), agência de propaganda e informação, subordinada a William Donovan. No entanto, o OCIAA já desempenhava essa missão na América Latina e Rockefeller atritou-se com Donovan. A América Latina foi invadida com várias publicações e diferentes programas radiofônicos e isso para Donovan era propaganda, coisa afeta à sua organização e não a de Rockefeller. Apesar disso, o OCIAA manteve a sua exclusividade para continuar fazendo propaganda na região, por determinação presidencial. Começou nesse período a intimidade de Rockefeller com técnicas que viriam a ser aperfeiçoadas e assimiladas pela Inteligência norte-americana, bem como o estreito relacionamento da elite com essa atividade, como depois veio a comprovar-se, com o preenchimento dos principais cargos do OSS e da CIA, e com o financiamento de operações. A CIA e parcela da elite empresarial americana estavam muito próximas. Esta tendência já estava evidenciada na estrutura da 
organização dirigida por Rockefeller, o OCIAA, considerado uma das agências americanas mais bem preparadas na época da guerra. A maior parte dos funcionários eram pessoas de confiança do coordenador. Rockefeller valeu-se de executivos de grandes empresas, gente que pudesse aplicar seus conhecimentos e preparar as Américas para a guerra e para a aceitação da hegemonia norteamericana. Era o caso de James W. Young, primeiro diretor do Departamento ou Divisão de Comunicações, diretor da Thompson, conhecida empresa de propaganda com sede em Nova Iorque. Don Francisco, diretor da prestigiada Divisão de Rádio, era executivo da Lord \& Thomas, outra poderosa empresa de propaganda, e contava com a colaboração de J.W.G. Olgilvie, vice-presidente da International Telephone and Telegraph (IT\&T). Karl August Bikel, que também trabalhou na Divisão de Comunicação, foi chefe da United Press, a conhecida UP, que influenciou fortemente o noticiário e a opinião pública brasileira. Rovensky, assistente para comércio e finanças, era (...) vice-presidente do Chase Manhatam Bank ${ }^{20}$.

A proximidade entre a CIA e empresários norte-americanos refletiu-se também na figura de Allen Dulles, que serviu como diretor da CIA de 1953 a 1961, e foi substituído por John A McCone. Dulles, que era irmão do secretário de Estado John Foster Dulles, dedicou mais da metade da sua vida profissional ao exercício da advocacia na Wall Street. McCone foi substituído em 28 de abril de 1965, pelo contra-almirante reformado William F. Raborn Jr, também ligado ao ramo empresarial. De 1958 a 1962, Richard M. Bissel Jr foi o vice-diretor da Divisão de Planos (DDP) ${ }^{21}$. Bissel havia sido um brilhante professor de economia em Yale. Richard McGarrah Helms foi vice-diretor da DDP em 1962, e foi nomeado DCI em junho de 1966; nasceu em St. David's, na Pensilvânia, um subúrbio elegante da Filadélfia, e foi criado em South Orange, Nova Jersey, um subúrbio da classe alta em Nova Iorque. O pai dele, Herman, foi diretor de vendas da corporação de alumínios ALCOA. Ray S. Cline, que foi contemporâneo de Helms como vicediretor de Inteligência, tinha os títulos de bacharel de Artes e doutor em Filosofia pela Universidade de Harvard. Cline foi substituído em 1966 por R. Jack Smith, que obtivera o título de bacharel de Artes na Universidade de Miami e o de doutor em Filosofia na de Cornell. Helms foi substituído como vice-diretor de Planos, em junho de 1966, por Desmond Fitzgerald. Formado pela St. Mark’s School, pelo Harvard College e pela Faculdade de Direito de Harvard, Fitzgerald tinha sido um próspero advogado na Wall Street com filiação ao clube Racquet and Tennis. Em 1939 casou-se com Marietta Endicott Peabody, neta do fundador da Escola Groton, onde estudou o presidente Franklin Delano Roosevelt. Antes de substituir Helms, Fitzgerald foi o representante da CIA na força tarefa latino americana, composta pelas agências de inteligência norte-americanas.

A riqueza e posição social dos altos funcionários da CIA tornou a agência um clube social fechado da alta classe. Os vinte principais cargos da CIA sempre foram preenchidos por funcionários procedentes das melhores universidades norte- 
americanas como Harvard, Yale e Princeton. Destes, uma percentagem significativa era oriunda das principais famílias dos Estados Unidos. Em 1966, o chefe do escritório da CIA em St. Louis nos últimos quinze anos tinha sido Louis Werner II, banqueiro de investimentos, diplomado pela St. Paul's School e por Princeton e pertencente à ilustre e rica família de St. Louis ${ }^{22}$. William H. Jackson, banqueiro de investimentos em Nova Iorque, que havia sido oficial de inteligência do OSS durante a Segunda Guerra e diretor-gerente da J.H. Whitney \& Co., veio a ser diretor-adjunto da CIA ${ }^{23}$.

Ao contrário do Brasil, onde a elite aliou-se ao Serviço Nacional de Informações (SNI) somente em determinado momento que lhe foi conveniente, a CIA, desde a sua criação, era dirigida por uma parcela representativa da elite americana. Os dirigentes do SNI eram oficiais das forças armadas em sua maioria oriundos da classe média. Quando o SNI estava tornando-se inconveniente para a elite, houve uma intensa campanha difamatória na imprensa. Criada a vinculação do SNI com a repressão política dos governos militares, o temor da opinião pública era de que tal organismo continuasse agindo como "polícia política” no ressurgimento da democracia no país. Em certa época, no Governo Sarney, o órgão de inteligência teve que ficar em quarentena por quase um ano para que, evitando possíveis escorregadelas, pudesse sair nos noticiários. A propaganda veiculada pelos meios de comunicação brasileiros contra o SNI, tinha um aparente objetivo: acabar com a credibilidade e, conseqüentemente, com a própria existência de tal organismo. Assim, em dezembro de 1998 uma revista de circulação nacional ${ }^{24}$ publicou uma reportagem de sete páginas intitulada “O nominado Jader”, cuja síntese contextualizava que "com trinta e nove acusações e vinte e seis bobagens, o prontuário do ministro Jader Barbalho no SNI revela um órgão desinformado e ineficiente”. Usando adjetivos com o nítido objetivo de levar o leitor a dar boas gargalhadas, acusava os seus agentes de "confusos”, "trapalhões" e importunadores de "figuras do primeiro escalão do próprio governo do qual faz parte”. Colocando em dúvida as denúncias de corrupção existentes no prontuário de Jader no SNI, a matéria não acusava o então ministro, mas desmoralizava cabalmente o órgão de inteligência. Em 2001, para não ser cassado pelo Senado por atos de corrupção praticados desde antes de 1988, o senador renunciou ao mandato (ver em www.senado.gov.br acusações contra Jader). Coincidentemente, resguardadas as diferentes conjunturas, anos antes a opinião pública norte-americana havia sido contaminada com as mesmas apreensões em relação ao OSS, o organismo de inteligência que havia atuado durante a Guerra. Os temores da mídia, baseando-se na premissa que tal organismo pudesse exercer o mesmo papel da Gestapo, aliado ao desinteresse do governo, levaram à extinção do OSS.

Embora o OSS tenha sido extinto, os Estados Unidos haviam amadurecido em questões de inteligência no pós-Guerra e empresários norte-americanos iriam dirigir a CIA por muitos anos. Envolvido em sérios apuros políticos com o fiasco da 
Baía dos Porcos (tentativa de invasão de Cuba organizada pela CIA), o presidente Kennedy nomeou, em janeiro de 1962, o conservador republicano John McCone como $\mathrm{DCI}^{25}$ em uma tentativa de acalmar a oposição. O multimilionário McCone recebia restrições de muitas pessoas quanto aos seus vultuosos lucros obtidos durante a Segunda Guerra na atividade de construção naval. Ralph E. Casey, do Escritório de Contadoria Geral, órgão de vigilância do Congresso, depôs em 1946 dizendo que McCone e seus sócios na California Shipbuilding Company tinham ganho quarenta e quatro milhões de dólares a partir de um investimento de cem mil dólares. Em janeiro de 1962, durante as audiências da Comissão das Forças Armadas em que se examinou sua nomeação, McCone prestou depoimento sobre o cargo de diretor que ocupara na Panama Pacific Tankers Company, grande frota transportadora de petróleo, e sobre o fato de possuir um milhão de dólares em ações da Standard Oil of California, que opera em larga escala no Oriente Médio, Indonésia e América Latina ${ }^{26}$.

Como é sabido, a Standard Oil é um conglomerado de empresas petrolíferas pertencente ao Grupo Rockefeller. Parte do treinamento dos oficiais de inteligência da CIA era a investigação dos empregados da Standard Oil na Venezuela, a fim de verificar antecedentes esquerdistas ou subversivos. $\mathrm{O}$ encarregado da segurança da Creole Petroleum, em Caracas, era um ex-agente do FBI intimamente relacionado com a CIA. No Uruguai, alguns executivos de empresas subsidiárias norte-americanas, entre as quais a General Eletric, reuniam-se, semanalmente com o chefe local da CIA, com o mesmo propósito ${ }^{27}$.

Essa intimidade entre a CIA e empresários norte-americanos aflora muito claramente no Brasil em começos de 1962. A CIA mantinha dois homens em Recife no Consulado americano. Outros agentes estavam infiltrados na Liga Cooperativa dos Estados Unidos da América (CLUSA) e no Instituto Americano para Desenvolvimento dos Trabalhadores Livres (AIFLD). Criado em começos da década de 60, o AIFLD era uma parceria entre a CIA, a AFL-CIO e cerca de sessenta companhias norte-americanas, inclusive a Anaconda Company, a IT\&T e a Pan American World Airwais. Seu objetivo, segundo o presidente Kennedy, era "evitar que Castro solapasse o movimento trabalhista latino-americano"28.

Nos anos de 1950 e 1960, as operações encobertas da CIA e das forças armadas norte-americanas cresceram de importância na medida em que a dinâmica da Guerra Fria expandia-se da Europa para a Ásia e o restante do Terceiro Mundo. No Governo Kennedy, a responsabilidade pela condução de operações paramilitares e de contra-insurgência passou a ser dividida com o Pentágono. Para enfrentar os distúrbios no sudeste asiático e América Latina, foi criado o Grupo de ContraInsurgência ou Grupo CI, com a principal missão de desenvolver métodos para promover a ordem interna em todo o mundo. A presidência do grupo foi entregue ao general Maxwell Taylor e dele participavam representantes de departamentos ministeriais e um delegado da CIA. "Das deliberações do grupo CI surgiram: as 
Forças Especiais; um novo tipo de treinamento de contra-insurreição nas escolas militares, do National War College para baixo; e novos currículos no Instituto de Serviço Exterior, destinados a aumentar a vigilância dos funcionários do Departamento de Estado, da CIA e dos oficiais das forças armadas no tocante a problemas de sublevação nos países em que operavam ${ }^{29}$. Os esforços da CIA com operações encobertas durante a Guerra Fria representam apenas uma parte das atividades da Comunidade de Inteligência com operações encobertas, "pois as forças armadas também estiveram envolvidas em operações especiais mais ou menos clandestinas, determinadas pela Casa Branca" ${ }^{30}$.

Em princípios de 1964, o general George Robinson Mather, comandante da delegação americana na Comissão Mista Militar Brasil/Estados Unidos e chefe do Programa de Assistência Mútua (PAM), disse, em palestra na ESG, que a principal ameaça que o Brasil estava exposto era a subversão interna, não havendo ameaças de fora do hemisfério. E para Mather o PAM estava aí para assegurar a existência de forças militares e paramilitares locais em condições de garantir a segurança interna, sem que houvesse a necessidade de uma intervenção militar direta dos Estados Unidos. Mather não disse, mas supõe-se que para uma intervenção militar dos Estados Unidos no Brasil, o amparo legal e político seria “arranjado” através do TIAR. Efetivamente, entre 1963 e 1964 o Brasil recebeu setenta e cinco milhões de dólares para o programa de treinamento policial e duzentos e seis milhões de dólares em ajuda militar. O treinamento dos militares brasileiros para capacitação em segurança interna compreendia operações e táticas de contraguerrilha; contra-insurreição; inteligência e contra-inteligência; inteligência de segurança pública; guerra psicológica; assuntos civis e governo militar; controle de distúrbios; e guerrilha na selva. As escolas militares norte-americanas haviam programado em 1961, 6.500 cursos para 5.200 militares oriundos da América Latina; em 1962 os cursos ofertados subiram para 7.000 a serem preenchidos por 5.600 alunos $^{31}$.

Brasileiros civis também eram treinados diretamente pela CIA. Em 1965, já funcionava em Fort Hollybird uma escola de inteligência da CIA para funcionários de governos de países aliados. Funcionários brasileiros passaram por aquela escola, como reconhece o próprio governo brasileiro ${ }^{32}$.

O primeiro treinamento em Inteligência organizado por uma instituição brasileira foi realizado pela ESG, em caráter experimental no ano de 1958, quando foi instalado o SFICI. Obviamente, toda a experiência que a ESG e os militares brasileiros possuíam nessa área havia sido repassada pelos norte-americanos, a partir do relacionamento militar mais estreito. Sob o comando do general Oswaldo Cordeiro de Farias, a ESG enviara para o National War College, em fins da década de 1940, os primeiros integrantes do seu corpo permanente. O grupo, que ficou conhecido como “Grupo Sorbonne”, era composto pelo General Antonio Carlos Muricy, os coronéis Jurandir Bizarria Mamede, Rodrigo Octávio Jordão Ramos, 
Alfredo Souto Malan e o tenente-coronel Golbery do Couto e Silva. Em 1950, Golbery foi classificado no Estado Maior do Exército. Em 1953, redigiu o "Manifesto dos Coronéis" contra a concessão de aumento de cem por cento para o salário mínimo, assinado por mais de oitenta oficiais influentes, que derrubou João Goulart do Ministério do Trabalho e o ministro da Guerra, general Estilac Leal, nacionalista e getulista; daí Golbery foi para a Casa Militar do presidente João Café Filho ${ }^{33}$.

A instalação do SFICI, somente doze anos após sido criado pelo decretolei que reajustou o Conselho de Segurança Nacional em 1946, leva-nos a acreditar que $o$ ato de sua criação foi mais por fruto da convivência com os americanos durante a Guerra, do que por visualização estratégica do alcance dessa ferramenta de governo. No entanto, em 1958, a pressão exercida pela Guerra Fria supostamente levou o Brasil a tomar um posicionamento nativo mais claro em questões de segurança interna. É o que se depreende da estrutura organizacional do SFICI, cujos esforços maiores estavam voltados para questões domésticas. O Setor de Contra-Informação (SCI), que a priori deveria identificar a espionagem estrangeira, acumulava funções burocráticas de segurança orgânica e estava inserido dentro da estrutura da Subseção de Segurança Interna (SSSI), numa evidente confusão de papéis que limitava em muito o alcance das ações. A competência do SCI estava estabelecida da seguinte maneira:

"propor normas para a segurança e fiscalização do Serviço de Informações; manter em dia o levantamento das atividades de pessoas físicas ou jurídicas que possam ter atividades contrárias aos interesses nacionais; manter em dia o levantamento da situação das agências que exploram no país as comunicações de qualquer natureza; participar do planejamento da contra-propaganda; e cooperar no planejamento que visa estabelecer controle sobre as zonas de segurança” ${ }^{34}$.

A inocência com que a atividade de inteligência era vista no Brasil, evidenciou-se desde o vácuo criado entre a idealização e o efetivo funcionamento do SFICI. Durante sua breve existência (1958/64). O SFICI funcionou precariamente com escassos recursos humanos e materiais e não pôde desempenhar em plenitude o seu mandato. Subordinado a uma seção da Secretaria Geral do Conselho de Segurança Nacional (CSN), o SFICI não possuía a necessária agilidade para integrar as informações e para fazê-las chegar com presteza às mãos do secretário geral, conforme reconheceu o governo na Exposição de Motivos que Castelo Branco enviou ao Congresso, junto com o projeto de lei que propunha a criação do SNI.

\section{Conclusão}

A confluência das ações aqui relatadas, nos encaminha para a conclusão que o NSC elaborou e colocou em prática uma eficiente estratégia de segurança, 
para respaldar a política de manutenção do Brasil como um dos suportes para o desenvolvimento da economia norte-americana. O Brasil, como de resto a América Latina, era visto como uma reserva estratégica que permitiria a continuidade, no futuro, do poderio econômico e militar dos Estados Unidos e, portanto, não poderia passar para a órbita de influência soviética e nem, tampouco, ficar sob um regime nacionalista forte, que viria fatalmente a descolar-se da influência exercida pelos Estados Unidos. Sob o ponto de vista industrial, o país tinha uma importância restrita, mas era muito importante como fonte fornecedora de matérias-primas de valor. Certamente faltou essa percepção às instituições políticas e governamentais brasileiras, ou, se houve, faltou capacidade de reação. O SFICI, que seria a instituição governamental brasileira com mandato para detectar essa estratégia, juntamente com o CSN, não dispunha de experiência, amparo técnico e administrativo e pessoal treinado para tal mister. O estamento militar brasileiro, envolvido em disputas políticas internas desde 1930, lamentavelmente também não teve essa percepção. Evidentemente tais ações tinham os objetivos dissimulados, o que dificultava a percepção. A maneira de dissimular tais ações foi institucionalizada em 1952, quando o governo dos Estados Unidos criou a expressão covert action (operações encobertas) para qualificar alguns meios pelos quais, desde a década de 1940, já vinha interferindo secretamente na política interna de alguns países. Embora as covert action sejam cobertas por um estratagema, de modo que não venham a ser atribuídas ao Estado patrocinador, muitas ações empreendidas pelos norte-americanos vieram a público, como foram os casos da Guatemala, Nicarágua, Irã, Itália, Chile e Vietnã, o qual acabou transformando-se em guerra ostensivamente declarada.

Também evidenciou-se, no período, a ausência de coordenação entre as políticas internas e externas dos governos brasileiros. Enquanto no âmbito externo buscava-se uma afirmação e independência em relação aos Estados Unidos, por mais paradoxal que seja, no âmbito interno as relações estreitavam-se cada vez mais, subordinando e influenciando o comportamento dos funcionários dos organismos de segurança e defesa. Era nítida a falta de comando do governo e da sociedade sobre tais instituições. Ganha destaque então, a seguinte questão: por que os governos norte-americanos empenhavam-se em treinar e oferecer assistência técnica contínua aos militares e policiais brasileiros, diante de um quadro de incompatibilidades políticas e econômicas com os governos instalados no Brasil? Simplesmente porque um dos mecanismos para um país conseguir controle político sobre outro Estado é, através de uma operação de contra-inteligência, penetrar no sistema de segurança desse outro país. Quando um determinado país treina a polícia, os órgãos de inteligência e ou as forças armadas de uma outra nação, as instituições beneficiárias passam a vincular-se àquele outro Estado para além de suas próprias fronteiras nacionais. Isso pode transformar as instituições de segurança do país beneficiário em atores subordinados na política global e, no decorrer do 
processo, fortalece ainda mais o controle do Estado estrangeiro sobre o Estado beneficiário.

A interferência em assuntos internos de outros países já era praticada pelos governos europeus antes do ano de 1500 . O verdadeiro propósito das relações exteriores é interferir na política de outros países, e Chefes de Estado há muito desenvolveram uma variedade de instrumentos para esta finalidade. Sendo de natureza secreta por razões óbvias, nem sempre estes instrumentos são exclusivos das agências de Inteligência, embora tais organizações geralmente tenham o mandato para assim agirem. Enquanto o objetivo do serviço de inteligência de qualquer Estado é reunir informações e analisar fatos à respeito de outros países, estes também estarão fazendo a mesma coisa em relação ao primeiro, furtando segredos e intrometendo-se em seus assuntos internos. Assim, se um serviço de inteligência não tiver condições de conter as interferências secretas dos Estados competidores, as suas informações e julgamentos não terão confiabilidade e credibilidade para o processo decisório; os segredos do governo estarão expostos e o serviço de inteligência poderá ser usado como uma preciosa ferramenta por potências estrangeiras. Iludir e confundir, fornecendo informações falsas e patrocinando propagandas desinformadoras (geralmente de cunho político e econômico), têm sido as principais táticas utilizadas contra os serviços indefesos.

Em algumas circunstâncias a maneira mais direta, mais curta de mudar um governo estrangeiro é ajudar alguém ou um grupo inclinado a efetuar um golpe de Estado. Os inclinados a tais coisas são às vezes encorajados por ajuda externa na empreitada, pela possibilidade de refúgio no exterior em caso de falha e pela promessa de ajuda externa na consolidação da vitória. Assim o bem mais procurado por políticos ambiciosos tem sido a benevolência dos Estados que exportam eficientes sistemas de segurança. A maneira mais comum de um governo afetar outro é construir um relacionamento especial com grupos de influência dentro do corpo político do outro.

Ver os outros como os outros nos vêem, olhar para cada mudança que fazemos de um ponto de vista de alguém que poderia tirar vantagem dele é o começo da prudência. Perguntar "como é que eu tomei conhecimento disto" e "o que poderia ter predisposto meu ponto de vista sobre tal assunto" são fundamentos da prudência. A Filosofia trata tais questões em Epistemologia. No âmbito das ações de governo é uma atitude de contra-inteligência, que se ampara em uma quantidade expressiva de técnicas para conhecer e neutralizar, ou minimizar, as hostilidades secretas. A contra-inteligência implica também em infiltrar o competidor para saber o que ele sabe, controlá-lo e induzi-lo a fazer o que desejamos.

Efetivamente os Estados Unidos obtiveram êxito ao manter o Brasil, forçosamente, dentro da Doutrina de Reserva Estratégica apoiada pela Doutrina de Contenção e pelo Programa Ponto Quatro e, conseqüentemente, garantiram o fornecimento de matérias-primas nas condições que desejaram. As políticas 
adotadas pelos governos brasileiros, vistas pelo ângulo do contencioso velado, foram tomadas pelo NSC como ameaças a segurança nacional norte-americana. O nacionalismo que restringia a remessa de lucros, o comportamento crítico em relação à política de isolamento de Cuba, o episódio da condecoração de Guevara, a preparação do reatamento com a URSS, a aproximação com a China e o namoro com o Movimento dos Não-Alinhados foram temas de aguda controvérsia. O Brasil, ao tentar implementar a política do nacional-desenvolvimentismo independente, contrariou os interesses dos Estados Unidos.

Qualquer política de desenvolvimento deve levar em conta que desenvolverse também significa aumentar a participação no comércio internacional, ocupar espaços, e nenhum Estado soberano cede espaços gratuitamente. Isso sugere que o planejamento e a execução das políticas de desenvolvimento não podem se sustentar sem uma ideologia de segurança nacional, entendida pela Constituição de 1988 como defesa nacional. Esse, ao nosso ver, é um dos fatores pelos quais a política do desenvolvimentismo independente não se sustentou, muito embora ela viesse a ser retomada alguns anos depois. Ao contrário, os Estados Unidos amparados por uma ideologia, uma estratégia e fartos recursos, conduziram com eficiência e eficácia a segurança interna brasileira, daí porque foram vitoriosos no contencioso que durou de 1946 a 1964.

Sob novos paradigmas, criados no pós Guerra Fria, relevantes questões estão em discussão na América Latina, como a ALCA e o "narco-terrorismo", o que não exclui no nosso entendimento, a questão subjacente, que continua sendo a garantia de acesso aos recursos naturais para o desenvolvimento. Portanto, não é prudente relaxar a vigilância. A motivação econômica e o modo como foi executado o recente golpe na Venezuela é um fator importante a ser considerado em qualquer análise mais profunda sobre o assunto. E sob este enfoque, revestem-se de importância especial as advertências do general Patrick Hughes, diretor da Defense Intelligence Agency (DIA) ${ }^{35}$, feitas em 1998, sobre as ameaças potenciais para seu país nos próximos vinte anos, entre as quais incluiu a escassez de matériasprimas e agressões ao meio ambiente. Citando a Amazônia como exemplo, Hughes disse que se o Brasil resolvesse fazer uso da região de forma prejudicial ao meio ambiente estadunidense, as forças armadas dos Estados Unidos deveriam estar prontas para interromper o processo imediatamente.

Outubro de 2002

\section{Notas}

1 OLIVEIRA, Avelino de; LEONARDOS, Othon. Geologia do Brasil. 2. ed. p. 33. In: FONSECA, Gondin. Que sabe você sobre petróleo? Rio de Janeiro: São José, 1955, p. 94-95.

2 TOTA, Antonio Pedro. O imperialismo sedutor. São Paulo: Companhia das Letras, 2000, p. 88. 
CERVO, Amado Luiz. Relações internacionais da América Latina: velhos e novos paradigmas. Brasília: IBRI, 2001, p. 99-101.

WAINER, Samuel. Jornalistas contam a história. Folha de São Paulo, São Paulo, 14 jan. 1979. Depoimento ao repórter Wianey Pinheiro.

6 HUGGINS, Marta K. Polícia e política: relações Estados Unidos/América Latina. São Paulo: Cortez, 1998, p. 81-82.

DREIFUSS, René. 1964: a conquista do Estado. Petrópolis: Vozes,1981, p. 79.

8 LANGGUTH, op. cit., p. 93.

9 COLBY, Gerard; DENNET, Charlotte. Thy will be done, Harper Collins ed., Correio Braziliense. Brasília, 3 mai. 1996.

REVISTA VEJA. O Livro do Ano. São Paulo: 1972.

O IPES veio a ser fundamental para a estratégia de tomada do poder em 1964. Para maiores informações sobre a participação do IPES e seus integrantes no movimento de 1964, ver DREIFUSS, R.A, op. cit.

LANGGUTH, op. cit., p. 91.

13 HUGGINS, op. cit., p. 72.

14 LANGGUTH, op. cit., p. 120.

15 HUGGINS, op. cit., p.

16 LANGGUTH, op. cit., p. 95.

CEPIK, Marco A .C. Serviços de inteligência: Agilidade e Transparência Como Dilemas de Institucionalização. 2001. Tese de doutorado - IUPERJ, Rio de Janeiro, p. 289.

WISE, David/Ross. O poder secreto. Rio de Janeiro: Nova Fronteira, 1967, p. 180.

TOTA, op. cit., p. 50-54.

TOTA, idem, p. 84-91.

A DDP era a repartição que cuidava das operações da CIA.

WISE, op. cit., p. 144-153.

WISE, David/Ross. O governo invisível. Rio de Janeiro: Civilização Brasileira, 1968, p.102.

REVISTA VEJA. São Paulo: 14 dez. 1988.

O DCI além da CIA dirige também a comunidade de inteligência norte-americana.

WISE, David/Ross. O governo invisível, op. cit., p. 203.

LANGGUTH, op. cit, p. 227.

LANGGUTH, idem, p. 90.

LANGGUTH, idem, p. 50.

CEPIK, op. cit., cap. 5, p. 3.

DREIFUSS, op. cit., p. 81, 115 e 116.

OLIVEIRA, Lúcio Sérgio Porto. A história da atividade de inteligência no Brasil. Brasília: ABIN, 1999, p. 50.

OLIVEIRA, idem, p. 33-34.

JORNAL DO BRASIL. Rio de janeiro: 28 fev./1 mar. 1999.

a) A Defense Intelligence Agency (DIA), subordinada ao secretário de defesa, funciona como agência central do subsistema de inteligência militar norte-americano. Para informações sobre a estruturação do subsistema de inteligência militar norte-americano e funcionamento da DIA, ver CEPIK, op. cit.

b) As advertências do general Patrick Hughes foram publicadas pela imprensa, o que motivou um protesto oficial do governo brasileiro e, em conseqüência, o desmentido de praxe do governo norte-americano. 
Resumo

O presente estudo parte da premissa de que, para garantir o acesso a fontes de matérias-primas, que lhe permitiriam manter o poderio econômico e militar no futuro, os Estados Unidos tinham a necessidade de possuir o controle sobre a segurança interna brasileira. Elencando fatos e situações que evidenciavam esse interesse econômico nas ações dos organismos governamentais norte-americanos, mesmo os que aparentemente não tratavam da questão, como é o caso da CIA e do Pentágono, o estudo busca amparo, embora superficialmente, nas doutrinas de contenção e de reserva estratégica para ao final concluir que, em razão da ausência de uma ideologia de segurança nacional e de mecanismos governamentais de alerta, a segurança interna brasileira foi conduzida pelos Estados Unidos durante as duas primeiras décadas da Guerra Fria.

\section{Abstract}

The present study parts from the premise that, in order to guarantee the access to the sources of raw materials, that would allow the USA to keep its economic and military power in the future, the USA needed to have the control over the Brazilian internal security. Electing facts and situations that evidenced this economic interest in the action of the American governmental organisms, even those that apparently did not deal with the question, as it was the case of the CIA and the Pentagon, the study searches the support, although superficially, of the doctrines of containment and strategic reserve, concluding at that, because of the absence of a national security ideology and of governmental alert mechanisms, the Brazilian internal security was conducted by the USA during the first two decades of the Cold War.

Palavras-chave: Política Exterior; Brasil; Estados Unidos; Segurança interna brasileira; Interesses econômicos norte-americanos.

Key words: Foreign Policy; Brazil; United States; Brazilian internal security; NorthAmerican economic interests. 